\title{
12. The interplay and tensions between justice claims: Nancy Fraser's conception of justice, empirical research and real world political philosophy
}

\section{Bert van den Brink, Miklós Zala and Tom Theuns}

\subsection{INTRODUCTION}

This volume took a real world political philosophy as its starting point (see Chapter 3) by adopting the tripartite distinction between justice as redistribution, justice as recognition, and justice as representation, taken from the work of Nancy Fraser (1995, 1997, 2005), as a starting point for conceptualizing justice (see Chapter 1). In Chapter 4 this framework was then developed, amended, and complemented by looking at different academic disciplines' theoretical conceptualizations of justice. A next step was to amend and complement the theory conducting empirical research (Chapters 5 to 11). The current chapter explores how in the course of the volume our understanding of justice developed and departed from Fraser's tripartite view.

Nancy Fraser's approach was developed from a 'non-ideal' theoretical, 'context-sensitive' approach in critical social theory. In that sense, methodologically, it is not far removed from the 'real world political philosophy' approach developed in Chapter 3 of this volume. We now will see in what way the empirical findings as presented in this volume confirm or contrast the Fraserian model. Our main thesis is that the empirical chapters help demonstrate, first, that Fraser's tripartite theory rightly points out some genuine tensions between justice claims, but also show that her tripartite conception is not wholly adequate, in the additional dimensions of justice and tensions that arise that her theory cannot account for.

This chapter starts with (1) an introduction to Fraser's position regarding the 'trilemma' of justice and the meta-value of parity of participation. Then 
it (2) engages her views on the interplay and tensions between justice claims. The chapter moves on to (3) analysing theoretical and empirical research on the conceptualization of justice. This enables us to (4) reflect on the extent the tripartite approach is applicable in light of the findings of our collaborative project.

\subsection{PARTICIPATORY PARITY AND THE TRILEMMA OF JUSTICE}

Fraser's tripartite understanding of justice has deep roots in European social and political theory, and more specifically the critical social theory of the Frankfurt School. These European roots are characterized by a rejection of prescriptive and utopian idealization (ideal theory) and by the philosophical articulation of normative criteria for evaluating justice claims from everyday practice and the history of social struggles (Habermas 1984/87; Honneth 1996).

Fraser has observed that this approach is characterized by a 'distinctive dialectic of immanence and transcendence' (Fraser and Honneth 2003, p. 202). This enigmatic phrase captures the idea that the standards for criticism of given social interactions are already present (or 'immanent') in those interactions (Thompson 2006, p. 12). Articulating ideals of justice is not in essence a matter of abstract theorizing, it is rather a matter of articulating ideals that are immanent in practice. By virtue of their normative force, these ideals 'transcend' those practices, giving them a critical and prescriptive edge.

Fraser's work offers a social-theoretical toolbox for understanding and addressing real world experiences of injustice caused by given institutional arrangements in society. At the heart of her 'dialectic of immanence and transcendence' sits the ideal of the parity of participation that demands that all members of society can participate as peers in social interaction. This principle starts from 'the equal autonomy and moral worth of human beings'; it is deontological and non-sectarian (Fraser and Honneth 2003, p. 229). This is the liberal core of Fraser's normative theory, which is immanent in the emancipatory social movements of late modernity (remember that in the US context, 'liberalism' as a term stands for a moderately progressive, civil rights-focused political view).

From liberal normative beginnings, Fraser's normative theory developed through deep social-theoretical insight into the dynamics of social and political struggle. It does not focus on liberal ideals and formal rights, but on their social and institutional implementation and realization. It is therefore unsurprising that redistribution, recognition, and representation are the dimensions of justice that Fraser focuses on (see also Chapters 1 and 4). Responding to constellations of injustice with 'restorative' strategies of redistribution, rec- 
ognition, and political representation of individuals and groups belongs to the standard repertoires of justice in modern welfare states and societies.

The distinction between economic and cultural injustice that is central to the approach is analytical (Fraser 1997, p. 15). However, while we may agree that both forms of injustice should be remedied in culturally diverse societies that are characterized by capitalistic market relations, the remedies they propose often seem to pull in different directions, leading to apparent tensions between justice claims. Whereas claims to cultural recognition draw attention to the specificity of group identity, redistributive claims 'often call for abolishing economic arrangements that underpin group specificity' (for instance, received interpretations of socio-economic roles for women and particular immigrant groups) (1997, p. 16; Fraser et al. 2004). The 'redistribution-recognition dilemma' states that '[p]eople who are subject to both cultural injustice and economic injustice need both recognition and redistribution. They need both to claim and deny their specificity' (p.16, emphasis added). We are also confronted with a frequent lack of fit between authoritative political forms of representation and state transcending forms of moral affectedness typical of contemporary forms of economic and cultural injustice (Fraser 2005, pp. $75 \mathrm{ff}$.). Adding the perspective of justice as representation results in what we may call a 'trilemma of injustice'.

The work collected in this volume has used these dimensions of justice as a fruitful starting point of analysis. The theory is multi-dimensional, articulates a principle of parity of participation that has great normative force, and leaves room for additional normative and empirical approaches to (in)justice. Perhaps the aspect of the multi-dimensional approach that has benefitted authors most is the insight into the entwinement of dimensions of (in)justice. The intertwining of recognition-based and redistributive injustices is aptly highlighted by Orsolya Salát (2019a, pp. 2-3, emphasis added):

While originally ... it was assumed that education would first of all affect issues of recognitive justice, the research shows more and more that the three aspects are not or cannot be meaningfully separated alongside rights, or at least in a rights framework.

The trilemma of injustice generates several kinds of interplay and tensions between justice claims. First of all, the redistribution-recognition dilemma serves to remind us that, when probing justice claims, it is important to always ask which consequences awarding more recognition for identity claims will have on people's socio-economic standing, and vice versa. Second, given that one dimension of justice cannot be reduced to the other, we need to acknowledge that tensions between justice claims cannot be made to disappear; if Fraser is right, they are here to stay. Third, as a matter of representation, even 
where we reach more or less justifiable balances between justice claims in social and political agreements, we need to be open to the possibility that the agreements reached do not fit the frame of the problem - that is, the scope both of all those who are subjected to injustice and of all those who deserve to be addressed by solutions.

\subsection{TRADE-OFFS BETWEEN DIMENSIONS OF JUSTICE}

The view that we have developed under the term 'real world political philosophy' (Wolff 2011; Van den Brink et al. 2018, pp. 10ff.) was informed by an investigation into non-ideal theoretical approaches to justice. These approaches are shared by theorists such as Andrea Sangiovanni $(2008,2016)$, David Wiens (2012), Jonathan Wolff (2011, 2015), among others, starting their investigation from a diagnosis and then aiming to provide a solution to the given problems (Chapter 3; Wolff 2011). In that sense, real world political philosophers are similar to a doctor who examines the patient first and then offers a cure to the patient's ailment (Van den Brink et al. 2018, p. 10). That is a different approach from thinking of problems of injustice in terms of dilemmatic conceptual oppositions, as Fraser is wont to do. The dilemmatic approach runs the risk of failing to recognize injustices as they meet us 'on the ground', rather than in a pre-given conceptual dilemma between conflicting analytical dimensions of justice.

Fraser has distinguished between 'affirmative' and 'transformative' strategies for repairing dilemmatic injustices. Affirmative remedies for injustice she presents as 'correcting inequitable outcomes of social arrangements without disturbing the underlying framework that generates them'. Transformative remedies, by contrast, are 'aimed at correcting inequitable outcomes precisely by restructuring the underlying generative framework' (Fraser 1995, p. 23). Whereas affirmative remedies, in her view, generally promote and solidify problematic group differentiations, either in terms of class or naturalized group identities, transformative remedies 'deconstruct' such differentiations and ask how they facilitate or obstruct cooperation of members of society as peers. The latter have her strong preference.

With this understanding of possible remedies to injustice in place, Fraser's account of justice and injustice becomes more than an analytical tool faced with a conceptual dilemma. In her 1995 seminal article, she associates affirmative strategies with the liberal welfare state and mainstream multiculturalism on the one hand and transformative strategies and deconstruction of group identity with socialism on the other hand (Fraser 1995). However, we have not found a prima facie reason why the liberal welfare state and mainstream multiculturalism could not be open to transformative politics. 
Take the case of home care, thoroughly discussed by Trudie Knijn. She argues for the restructuring of the care sphere, promoting what she labels the 'chain model' of care. The chain model aims to 'stimulate capabilities of ageing individuals and the ones that care for them in whatever setting to avoid becoming and be treated as passive dependents' (Knijn 2019, pp. 48-9). She reports that in the Netherlands, for example:

the ... chain of care exemplifies a stepwise regulated and assessment based chain of care from the very light forms of care (housekeeping assistance) to more severe forms of care (care and nursing at home paid for by mandatory health insurance) and the most intensive form of care (individualized residential). Such a chain, if well-functioning, offers a tailor-made trajectory of recognition of care needs that is accessible on the basis of assessment, no matter one's income, thus complies to redistributive justice claims. In all other countries in our study the chain is broken, fragmented and disturbed. Elements are missing in the recognition of care needs and the redistribution of the costs of care. (Knijn 2019, pp. 48-9)

It would amount to a significant reform of the care sphere if the chain model were to be applied (including in the Netherlands, which does not fully satisfy the chain model's criteria). For it would significantly reshape the boundaries of the public and private spheres. But, in contrast with Fraser's view, we think that this kind of fundamental reshaping of important boundaries such as the public/private one can be made within the purview of the welfare state.

As Elizabeth Anderson (2008) points out, many aspects of public policy are not adequately captured by Fraser's original two dimensions of redistribution and recognition, which Anderson illustrates in a discussion of affirmative action for African-Americans. She concludes that, once we recognize the correct rationale for race-based affirmative action, an affirmative-redistributive policy will no longer work against recognition (2008, p. 171). And, what is equally important, the affirmation-recognition of the group will not be based on the group's cultural distinctiveness (Anderson 2008, pp. 166-7). For Anderson, this dissolves Fraser's dilemma. And indeed, it dissolves a blindness of the dilemmatic 'pull in two directions' proposed by Fraser. The pull in two directions is not so much there in reality; it is rather a result of how reality is conceptualized by the theorist of justice.

Furthermore, empirical research done into the education of children with special needs (Salát 2019a, pp. 44-6; see also Chapter 6) and reflections on how different metrics of justice play into affirmative and transformative strategies (Buğra and Akkan 2019; see also Chapter 9) show that wholesale transformative approaches to injustice are often not reachable. Through their general and idealized agendas, they run the risk of neglecting the strong need for improving individual situations of persons in the here and now (Robeyns 2008). In conclusion, while Fraser's distinctions are analytically helpful, we 
ought to remove the perhaps all-too-ideological categorizations of liberal welfare state and mainstream multiculturalism with affirmation of the status quo, and socialism and deconstruction as the only truly transformative remedies.

One fundamental insight that is not captured by these categorizations in Fraser's earlier work (1995) is that the functional role of ready-made substantive theories of social justice might be replaced by theories of democratic justice, which treat justice as a subject of democratic deliberation rather than as a theoretical issue (Fraser 2005, pp. 86ff.; cf. Habermas 1996; Forst 2011). Seen in this way, which Fraser now embraces, we hold the principle of parity of participation to have both a substantive evaluative role - specifying a desired end-state by which social arrangements may be evaluated - and to serve as a procedural standard by which 'all affected' can determine whether the norms and expectations by which they are governed are legitimate. Rather than looking at constellations of injustice through schematic categorizations, the imperative is to build a piecemeal theory of justice for particular constellations, as has been done for immigration (Cole and Heath Wellman 2011), the regulation of drugs (Husak and de Marneffe 2005), gambling (Wolff 2011; see also Chapter 3), prostitution (de Marneffe 2010), or same-sex marriage (Corvino and Gallagher 2012; cf. Van den Brink et al. 2018, p. 10).

Our approach to real world political philosophy of justice, then, focuses on elucidating and repairing specific constellations of injustice in the here and now. What seems to be needed is a combination of the best possible affirmative strategies that open up what may seem 'second best' remedies in everyday life, with an analysis of the need for deeper restructurings of the institutional context.

\subsection{THE TRIPARTITE UNDERSTANDING OF JUSTICE IN LIGHT OF THEORETICAL AND EMPIRICAL RESEARCH}

Our joint focus for the work collected in this volume was deliberately limited to real world, manifest injustices in Europe. As far as the empirical work is concerned, this set the scope for the range of justice concerns that were examined in six countries: Austria, Hungary, the Netherlands, Portugal, Turkey, and the United Kingdom. The identification and analysis of these contemporary European problems was not only done from the perspective of different academic disciplines, but also with a diverse methodological toolkit. These methodological tools, to name a few, included the analysis of legal texts, the discourse analysis of national newspapers and politicians' speeches, focus groups and ethnographies. 
A core question is what we can expect from the empirical research regarding conceptualizations of justice. Social science is unable to provide the criteria that enable us to judge 'who and what counts' from the point of view of justice, and who and what does not. We agree with Fraser that 'such judgments necessarily involve a complex combination of normative reflection, historical interpretation and social theorizing' (Fraser 2009, p. 292). Empirical data must be combined with normative premises in order to be able to reach normative conclusions (Van den Brink et al. 2018; see also Chapter 3). For this reason, the empirical research has aimed to look at justice and fairness through the threefold Fraserian lens of redistribution, recognition, and representation. The application of this three-dimensional desideratum is not straightforward, however. The previous chapters frequently report that the examined countries understand the same justice-related issues differently; guarantee different rights and entitlements, and confront vulnerable groups with different demands. They also justify the treatment of these vulnerable groups from different normative considerations. The chapters do not show that approaching these institutional, social, and cultural contexts from one normative framework of justice is straightforward or likely to be successful.

Therefore, our collaborative project shows that we have to complete and adjust Fraser's framework in at least three different regards. First, the Fraserian categories are incomplete because there are further important dimensions of justice beyond the 'three Rs', which are relevant in the European context. Second, Fraser's approach sometimes requires additional explanatory and normative work. For Fraser's tripartite conception is not always fine-grained enough to diagnose complex real world injustices. Third, justice in Europe requires an alternative framing of justice to Fraser's, specifically, one that can justify this special mid-level in between full-blown global justice and the nation state. Let us see these difficulties in more detail.

Starting with dimensions: while the Fraserian tripartite conception is certainly an illuminating framework in general, these three categories often miss important aspects of injustice. Empirical research points to dimensions that do not fit well to Fraser's categorization, such as redressing historical injustice (Akkan and Hiah 2019), epistemic injustice (Lepianka 2019), and justice understood as capabilities (Buğra and Akkan 2019; Lepianka 2019). Historical injustice and the politics of commemoration exhibit a complexity that redistribution, recognition, or representation cannot easily theorize (Akkan and Hiah 2019). The reason for this is that rectifying historic injustices falls under the category of corrective justice, sometimes but not always related to Fraser's relational egalitarian goal of participatory parity.

Epistemic injustice as a missing dimension is discussed by Dorota Lepianka (2019). Epistemic injustice has two important versions, testimonial injustice and hermeneutical injustice (Fricker 2007). Regardless of the specific 
definition or form, epistemic injustice is generated by stereotypes and prejudices about marginalized groups and derives from unequal power relations (Lepianka 2019). At the end, those who are considered highly credible as 'knowers' are usually drawn from privileged groups.

On a closer look, these epistemic power relations are beyond the scope of Fraser's dimensions. For example, hermeneutical injustice, which refers to the phenomenon of the privileged sometimes lacking adequate conceptual resources to adequately discuss some forms of injustice, comes closest to being a problem of misrecognition, but it has important aspects beyond recognition. Withholding the conceptual resources to talk about injustice is a special type of injustice, but it is not misrecognition as such.

The capabilities approach (Sen 1992; Nussbaum 2000) appears to enjoy quite some take-up among empirical researchers (Anderson 2020; Buğra and Akkan 2019) while Fraser herself considers her approach as a broader capability view (Fraser 2007, p. 319). Surprisingly though, on reflection the capability view might actually be an alternative to Fraser's three-dimensional view. Bridget Anderson (2020), for example, references Ingrid Robeyns (2008), who puts forward her capabilities approach defending distributive justice in opposition to Fraser. Robeyns's (2008) critique is that Fraser supports only social capabilities, and not individual functionings (Fraser 2007, p. 319). Robeyns shows that this view is implausibly narrow: some personal functionings, like being well fed or educated, are inherently valuable, regardless of their social contribution to equal status (Robeyns 2008).

A second insight is that Fraser's theory needs additional explanatory and normative work, because her three proposed dimensions can be insufficient to diagnose certain injustices. Consider the case of justice in education and the problems of the Roma. In the case of education, participatory parity is an incomplete principle for justice in education (Chapter 9). As far as the Roma are concerned, the Fraserian framework faces difficulties when confronted with the diverse injustices experienced by this group. In other words, both issues are more complex than Fraser's three-dimensional categorization allows. Let us take a look at these two issues in turn.

Regarding education, Orsolya Salát looks through the lens of Fraser's three justice concerns and finds the intersection of redistributive and recognitive problems (Salát 2019a, pp. 4-6). But she also exposes problems that are more difficult to theorize within Fraser's scheme. Regarding schooling for disabled children, she highlights that 'no system examined here fully realizes inclusive education or even sees it possible for everyone. All countries maintain the possibility of sending pupils with disability[ies] into segregated education' (Salát 2019a, p. 44). For example, in the case of Austria, an otherwise wealthy European country, Salát mentions that while the attempt to provide inclusive education can be seen in the creation of the so-called 'model regions for 
inclusive education', the 'implementation in the model regions ... do not demonstrate unequivocal success, and it seems especially clear that an important obstacle to realize a well-functioning inclusive school is lack of resources in terms of finances, infrastructure, time, and personnel' (Salát 2019a, p. 23). In our view, the lesson here for how we ought to conceive of justice is that while Fraser's approach is deliberately non-ideal theoretical, her theory of participatory parity forgets the 'theory of the second-best' (cf. Margalit 1996; Wolff 2011). Maximizing justice - in this case, participatory parity - certainly would require the widest possible inclusion of children with disabilities. But it might be the case that, in certain situations, investing more in the already functioning (and less inclusive) system leads to better educational results for disabled children. Of course, we do not want to suggest that this is certainly and always the case. But Fraser's theory of participatory parity seems to overlook the importance of incremental transitions away from manifest injustices in the real world (Sen 2010; Van den Brink et al. 2018).

Theorizing the situation for the Roma is not only a challenge to Fraser, but also to all Western political theorists (see Kymlicka 2002). Bridget Anderson (Chapter 8) analyses the case of the Roma in Europe and finds that 'in the current European context, Roma is a contested, multidimensional and highly racialized identity which simultaneously evokes material poverty, racialized phenotypes, and cultural practices' (Anderson and Dupont 2018, p. 4). They also find that whereas there is a continued attempt in the European Union (EU) since the 1990s to enhance the representation of this disadvantaged minority group, 'the results have been ambiguous' (Anderson and Dupont 2018, p. 4).

On the one hand, in some national and municipal contexts, those who identify as Roma have the right to elect Roma representatives in local, regional, and national governments, and Roma civil society leaders have had opportunities to influence policymaking through permanent and ad hoc consultative mechanisms. There have also been attempts to symbolically recognize Roma history, including their persecution, in official discourses. On the other hand, these measures do not seem to have translated into substantive representation, to the extent that Roma interests and perspectives continue to be widely overlooked by public authorities.

Anderson and Dupont are not the only ones, of course, who observe the complexity of the situation of the Roma (Kymlicka 2002). Fraser considers the Roma as an example of unjust exclusion that is a result of 'the combined operation of culture and political economy' (Fraser 2007, p. 316). As such, 'status hierarchies map onto class differentials to prevent some actors from participating at all in mainstream arenas of social interaction' (Fraser 2007, p. 316). But, as Kymlicka (2002, p. 75) points out, it is not clear what these 'mainstream arenas' should be: for instance, should the Roma be defined as a national or a transnational minority? Fraser's approach of participatory parity 
cannot provide a clear answer to this question - we must again look elsewhere for theoretical resources.

But Fraser's approach requires important complementary work in another regard as well. Here, the shortcoming of the tripartite conception of justice is not that it cannot capture the complexity of certain justice-related phenomena, but that these dimensions overlook an important site, or medium of justice: law. This is especially problematic in the European context. Tom Theuns (2018) has analysed the legal rules and practices regulating the exercise of the right to vote in local, national, and EU elections of marginalized groups, such as convicted prisoners, disabled persons, and immigrants. A large part of Theuns's analysis fits to Fraser's framework, but the lacunas are telling too. To wit, differences among the six countries regarding, for example, the voting rights of convicted prisoners are based on principles, not merely different, unreflective practices. For example, Theuns emphasizes that the United Kingdom's legal system approaches the question of voting rights regarding both convicted prisoners and (mentally) disabled persons in epistemic terms, unlike other countries (Dupont 2019). This might be described as an instance of recognitive injustice, but only if the epistemic justification is refuted. Fraser's theory, on the other hand, does not engage or respond to the matter of epistemic concerns for matters of representation and political rights. Similar problems arise regarding franchise for non-citizen residents and non-resident citizens. Theuns also discusses the case of dual citizenship of kin minorities, which, in the case of Hungary (Salát 2019b), has led to an interesting twofold problem: one being the question of the permissibility of external voting, the other the unequal voting rights for these external voters/dual citizens (Bauböck 2007; Theuns 2018). This shows that our tripartite justice concern is complicated by the different national-supranational legal frameworks which sometimes overlap, and sometimes clash, and Fraser's approach does not provide us with tools to discuss these difficulties in adequate detail. The core problem here, as William Scheuerman (2017) aptly observes, is that Fraser tends to ignore fundamental questions of law. As such, Scheuerman points out, she cannot provide answers to important questions regarding the law; in his words:

I remain rather skeptical that 'participatory parity' can get us far enough in grappling with the nuances of modern law or rights ... Could we, for example, usefully rely on the idea of participatory parity to develop a sophisticated defense of negative or 'liberal' liberties? Or even some basic concept of legal personality, arguably a constitutive feature of modern subjectivity? How far could participatory parity go in analyzing modern criminal or private law (property, contracts), or even international law, a legal arena in which many key principles and practices seem disconnected from Fraser's radical democratic normative starting point? (Scheuerman 2017, p. 153) 
One might wonder what a Fraserian approach to the European multi-level legal order, with the interplay of international law, EU law, national law, and regional law, would look like. In other words, law provides an important site and medium to articulate, and often regulate and execute justice claims (both on the European and national level). Disregarding the complex system of law leads to feasibility concerns for a theory that aims to provide solutions to problems here and now.

Our final area where we found the need to move beyond Fraser's framework is that, in an important sense, justice for Europe seems to require an alternative 'framing' of justice than Fraser prescribes. Fraser (2009) thinks that today we live in the time of 'abnormal justice'; the Westphalian framework is no longer exclusive, but relevant other frameworks are also present, and gaining in importance and support. Thus, Fraser extends the idea of the injustice of participatory imparity beyond the traditional framework of the nation state. When this happens, that is, when a framework excludes people who should be represented by it, we are dealing with 'misframing' (Fraser 2009). The idea of (mis)framing arenas of justice allows the theorist to 'map' the adequate 'political space' for theorizing justice (Fraser 2009). Against approaches of global justice based on mere personhood - such as the approach of Martha Nussbaum (1996) - or the idea of all-affectedness - like Peter Singer's (2004) view - Fraser defends a meta-principle of 'all-subjectedness', which holds that 'all those who are jointly subject to a given governance structure have moral standing as subjects of justice in relation to it' (Fraser 2009, pp. 292-3).

To a large extent, the difficulty for justice in Europe arising from the work gathered in this volume is the mapping of adequate political space - this is an important issue that Fraser aptly realizes. But her offered solution of the all-subjectedness principle cannot provide solutions to pressing European questions of justice regarding this mapping. How can we justify the existence of the EU? Why should richer countries in the EU support Bulgaria, for example, instead of African countries that are worse off (Van Parijs 2019)? On subjects such as these, Fraser's all-subjected principle yields no answer.

Van den Brink et al. (2018) suggest that something like Andrea Sangiovanni's practice-dependent view of justice might be applicable to the case of justice in Europe. Sangiovanni (2013) tries to find an answer to 'the point and purpose' of the EU. He holds that the raison d'être of the EU is to provide important insurance for member states against the risks of the mechanism of European integration itself. As such, he accepts the limited distributive nature of the EU based on the facts of European integration. We disagree with his favoured direction of the EU, but not with his mapping of the European political space, that is, that the EU is a political unit and arena that we have reason to focus on. In other words, whatever we think about the appropriate level of redistribution within member states of the EU, Sangiovanni is right that first we have to 
understand what is the history and function of this political-economic union. Again, Fraser's attempt to provide a realistic political theory for responding to injustice is underspecified for a real world situation. The more nuanced, Europe- (and EU) focused analyses of Sangiovanni and Van Parijs reveal challenges for theorizing justice in Europe which seem not to be on Fraser's US-inspired radar.

\subsection{THE INTERPLAY AND TENSIONS BETWEEN JUSTICE CLAIMS}

So, what we have found is this. Analysing questions of injustice and justice in terms of three dimensions - redistribution, recognition, and representation - and two strategies - affirmation and transformation - has been fruitful. As a heuristic tool, Nancy Fraser's framework helps articulate real world concerns about injustice in light of an ideal implicit both in everyday experiences across Europe and in the main institutions of state and society: that each member of society should be treated as a peer in social cooperation.

Our joint empirical and conceptual research in the current volume has been wide-ranging. So it does not come as a surprise that we have found that Fraser's dilemmatic approach to the multi-faceted understanding of justice often seems schematic and has limitations when brought to the analysis of policy decisions and normative theory. In analysing concrete injustices in Europe, we concluded that Fraser's instructive analytical tool requires both additional normative and empirical work and is often in need of alternative and more fine-grained approaches in normative theory.

At its core, the theory invites awareness of the fact that awarding more recognition for identity claims will also have consequences for the socio-economic standing of members of society, and vice versa. Second, it makes clear that the tension between justice claims cannot be made to disappear by being reductionist about what justice is. Third, even where we reach more or less justifiable balances between justice claims in social and political agreements, we need to be open to the possibility that the agreements reached do not fit the frame of the problem - that is, the scope both of all those who are subjected to the problem of injustice and of all those who deserve to be addressed by solutions. We found that when formulated in terms of catchy 'dilemmas' of justice, the social world may appear as an inescapably tragic universe in which, whatever those affected by injustice will do, they end up in trade-offs by which victims of injustice either lose their sense of identity and self or their socio-economic status.

Despite Fraser's non-ideal orientation, her trilemmatic approach to justice is tied to a near utopian, end-state vision in that injustices are best addressed through the deep restructuring of society on the socio-economic and political 
level and the deconstruction of collective identities on the recognitive level. This is the point at which the empirically sensitive approach of real world political philosophy takes a different turn. A standard conceptual taxonomy of the ways theories of justice can be ideal or non-ideal distinguishes between three sometimes overlapping metrics (Van den Brink et al. 2018; see also Chapter 3): the degree to which a theory assumes 'full compliance', is 'fact-sensitive', and is directed to an 'end-state'. Fraser's approach is non-ideal on the first two metrics: it accepts that facts about socio-economic, cultural, and political dimensions of identity determine justice concerns all the way down. But on the third metric it is firmly focused on end-state rather than transitional considerations. Indeed, a socialist agenda of deep economic restructurings and a deconstructivist approach to collective identity sets the horizon for the transformation of society and overcoming of injustice in Europe. When confronted with Europe's deep political and cultural pluralism, this substantive focus on a socialist and post-traditional horizon of end-state justice sits uneasily with findings in both the normative and the empirical work gathered in this volume. It also sits uneasily with an often neglected aspect of Fraser's own theory, that is, its openness to a theory of democratic justice and her professed anti-sectarianism.

Seen as a theory of democratic justice, Fraser's own interpretation of what the principle of parity of participation demands will play a substantive and partial (socialist, deconstructivist) evaluative role while supporting a procedural standard by which all affected by a constellation of injustice - including those who would not follow the socialist and deconstructivist agenda - can determine whether the norms and expectations by which they are governed can be accepted as legitimate. Rather than presenting an objective framework for all theories of justice, the theory will then be seen as one among several normative theories that theorists and policymakers can appeal to when analytically making sense of and normatively seeking solutions to injustices in society. The results of that will have to be brought in democratic debate with those subject to the injustices and the policymakers through lenses of redistribution, recognition, and representation.

This reading of Fraser's theory brings it closer to the real world political philosophy strategy that the philosophical work in the present volume has developed. As we have shown earlier, an empirically informed yet monolithic European theory of justice and fairness is not feasible (Van den Brink et al. 2018). Empirically informed and action-guiding theories of justice need to be case-based: geared to helping us better understand, evaluate, and recommend responses to European injustices. Such theories combine solid normative reasoning with empirical research and policy analysis in order to comprehend 'why [a policy area] generates moral difficulties, and then to connect those dif- 
ficulties or dilemmas with patterns of philosophical reasoning and reflection' (Wolff 2011, p. 9).

The interplay and tensions between justice claims are always strongly contextual. Real world political philosophy starts from identifying gross injustices from a set of overlapping perspectives inspired by reasonable and publicly shared normative principles like the principle of parity of participation. The hope is that reasonable views will be able to unite against identifications of what is manifestly unjust, even when they do not agree on what perfect justice would be. Reasonable people will accept that it is unjust when disabled persons are not able, as a result of their disability, to exercise their right to vote. These same people may well disagree about why this is unjust. Some may claim it violates human rights, others may claim procedural democratic justice is harmed, still others may view it as blatant discrimination. But regardless of why people consider it to be unjust, it is possible to build a coalition around the finding that it is, and that a solution needs to be found where disabled persons are de facto disenfranchised.

This approach is in parallel with what Cass Sunstein (1994) labels 'incompletely theorized agreements'. Sunstein's main focus is on law and legal decisions but his point is generalizable. In his view, there are three possible levels of disagreement (Sunstein 1994, pp. 1739-42; Howard 2019, p. 32). People might disagree about an abstract theory, they can disagree about mid-level principles, and they can disagree about particular outcomes. Sunstein proposes the type of incompletely theorized agreement where there is an agreement about the actual outcomes, and people are in favour of the outcome from various abstract theories and perhaps even from mid-level principles. We hold that real world political philosophy embraces this type of incompletely theorized agreement. Thus, Fraser's theory is an important lens through which we can analyse justice in Europe, but often what is more important is that there is a convergence regarding a policy outcome (such as affirmative action in education) that helps eliminate injustice here and now. Being ecumenical, we believe that this is a strength, and not a weakness of real world political philosophy.

\section{REFERENCES}

Akkan, Başak and Jing Hiah (2019), 'Historical memory and the practice of commemoration in public space - mapping moral sentiments of opinion leaders', ETHOS report D4.5, accessed 14 September 2019 at https://www.ethos-europe.eu/.

Anderson, Bridget (2020), 'Justice, care and personal assistance', ETHOS report D5.3, accessed 9 September 2019 at https://www.ethos-europe.eu/.

Anderson, Bridget and Pier-Luc Dupont (2018), "How does it feel like to be a problem?" What we can learn about justice as political representation from empir- 
ical case studies', ETHOS report D5.2, accessed 12 August 2019 at https://www .ethos-europe.eu/.

Anderson, Elizabeth (1999), 'What is the point of equality?', Ethics, 109 (2), 287-337.

Anderson, Elizabeth (2008), 'Affirmative action and Fraser's redistribution-recognition dilemma', in Kevin Olson (ed.), Adding Insult to Injury, London: Verso, pp. 164-75.

Bauböck, Rainer (2007), 'Stakeholder citizenship and transnational political participation: a normative evaluation of external voting', Fordham Law Review, 75 (5), 2393-447.

Buğra, Ayse and Basak Akkan (2019), 'Discourses on minorities' (and vulnerable groups) access to education, inclusionary and exclusionary aspects', ETHOS report D4.3, accessed 14 September 2019 at https://www.ethos-europe.eu/.

Cole, Phillip and Christopher Heath Wellman (2011), Debating the Ethics of Immigration: Is There a Right to Exclude? New York: Oxford University Press.

Corvino, John and Maggie Gallgher (2012), Debating Same-Sex Marriage, Oxford: Oxford University Press.

De Marneffe, Peter (2010), Liberalism and Prostitution, New York: Oxford University Press.

Dupont, Pier-Luc (2019), 'The right to vote for disabled persons and citizens living abroad: UK report', ETHOS country report for ETHOS report D3.4, accessed 10 November 2019 at https://www.ethos-europe.eu/.

Forst, Rainer (2011), The Right to Justification: Elements of a Constructivist Theory of Justice, New York: Columbia University Press.

Fraser, Nancy (1995), 'From redistribution to recognition', New Left Review, I (212), 68-93.

Fraser, Nancy (1997), Justice Interruptus. Critical Reflections on the 'Postsocialist' Condition, New York and London: Routledge.

Fraser, Nancy (2005), Scales of Justice: Reimagining Political Space in a Globalizing World, New York: Columbia University Press.

Fraser, Nancy (2007), 'Identity, exclusion, and critique: a response to four critics', European Journal of Political Theory, 6 (3), 305-38.

Fraser, Nancy (2009), 'Who counts? Dilemmas of justice in a postwestphalian world', Antipode, 41 (1), 281-97.

Fraser, Nancy and Axel Honneth (2003), Redistribution or Recognition? A Political-Philosophical Exchange, London and New York: Verso.

Fraser, Nancy, Hanne Marlene Dahl, Pauline Stoltz, and Rasmus Willig (2004), 'Recognition, redistribution and representation in capitalist global society: an interview with Nancy Fraser', Acta Sociologica, 47 (4), 374-82.

Fricker, Miranda (2007), Epistemic Injustice: Power and the Ethics of Knowing, Oxford: Oxford University Press.

Habermas, Jürgen (1984/87), Theory of Communicative Action, vols I \& II, trans. Thomas A. McCarthy, Boston, MA: Beacon Press.

Habermas, Jürgen (1996), Between Facts and Norms: Contributions to a Discourse Theory of Law and Democracy, Cambridge, MA: MIT Press.

Honneth, Axel (1996), The Struggle for Recognition: The Moral Grammar of Social Conflicts, trans. Joel Anderson, Cambridge, MA: MIT Press.

Howard, Jeffrey (2019), 'The public role of ethics and public policy', in Annabelle Lever and Andrei Poama (eds), The Routledge Handbook of Ethics and Public Policy, London and New York: Routledge, pp. 25-36.

Husak, Douglas and Peter de Marneffe (2005), The Legalization of Drugs, Cambridge: Cambridge University Press. 
Knijn, Trudie (2019), 'Boundary lines between private and public care: living independently at home or in a home', ETHOS report D5.4, accessed 12 October 2019 at https://www.ethos-europe.eu/.

Kymlicka, Will (2002), 'Western political theory and ethnic relations in Eastern Europe', in Will Kymlicka and Magda Opalski (eds), Can Liberal Pluralism be Exported?: Western Political Theory and Ethnic Relations in Eastern Europe, Oxford: Oxford University Press, pp. 13-106.

Lepianka, Dorota (2019), 'Mapping the construction of justice and justice related tensions in Europe - a comparative report', ETHOS report D4.4, accessed 14 October 2019 at https://www.ethos-europe.eu/.

Margalit, Avishai (1996), The Decent Society, Cambridge, MA: Harvard University Press.

Nussbaum, Martha (1996), For Love of Country? Boston, MA: Beacon Press Books.

Nussbaum, Martha (2000), Women and Human Development: The Capabilities Approach, Cambridge: Cambridge University Press.

Robeyns, Ingrid (2008), 'Is Nancy Fraser's critique of theories of distributive justice justified?', in Kevin Olson (ed.), Adding Insult to Injury, London: Verso, pp. 176-96.

Salát, Orsolya (2019a), 'A comparative report on the right to education: an assessment of the legal framework of six countries from the perspective of recognitive and redistributive justice', ETHOS report D3.6, accessed 18 October 2019 at https:// www.ethos-europe.eu/.

Salát, Orsolya (2019b), 'Hungarian report: the right to vote of persons with disabilities and citizens living abroad', ETHOS country report for ETHOS report D 3.4, accessed 12 November 2019 at https://www.ethos-europe.eu/.

Sangiovanni, Andrea (2008), 'Justice and the priority of politics to morality', Journal of Political Philosophy, 16 (2), 137-64.

Sangiovanni, Andrea (2013) 'Solidarity in the European Union', Oxford Journal of Legal Studies, 33 (2), 213-41.

Sangiovanni, Andrea (2016), 'How practices matter', Journal of Political Philosophy, 24 (1), 3-23.

Scheuerman, William (2017), 'Recognition, redistribution, and participatory parity: where's the law?', in Banu Bargu and Chiara Bottici (eds), Feminism, Capitalism, and Critique: Essays in Honor of Nancy Fraser, Cham, Switzerland: Palgrave Macmillan, pp. 139-57.

Sen, Amartya (1992), Inequality Reexamined, Cambridge, MA: Harvard University Press.

Sen, Amartya (2010), The Idea of Justice, Cambridge, MA: Harvard University Press.

Singer, Peter (2004), One World: The Ethics of Globalization, New Haven, CT: Yale University Press.

Sunstein, Cass R. (1994), 'Incompletely theorized agreements', Harvard Law Review, 108, 1733-72.

Theuns, Tom (2018), 'A comparative study on the right to vote for convicted prisoners, disabled persons, foreigners and citizens living abroad', ETHOS report D3.4, accessed 14 December 2018 at https://www.ethos-europe.eu/.

Thompson, Simon (2006), The Political Theory of Recognition. A Critical Introduction, Cambridge: Polity.

Van den Brink, Bert, Simon Rippon, Tom Theuns and Miklós Zala (2018), 'Report on the workshop "Ideal and non-ideal theories of justice": towards a non-ideal theory of justice in Europe', ETHOS report D2.2, accessed 12 February 2019 at https://www .ethos-europe.eu/. 
Van Parijs, Philippe (2019), 'Just Europe', Philosophy \& Public Affairs, 47 (1), 5-36.

Wiens, David (2012), 'Prescribing institutions without ideal theory', Journal of Political Philosophy, 20 (1), 45-70.

Wolff, Jonathan (2011), Ethics and Public Policy: A Philosophical Inquiry, New York: Routledge.

Wolff, Jonathan (2015), 'Social equality and social inequality', in Carina Fourie, Fabian Schuppert and Ivo Wallimann-Helmer (eds), Social Equality: Essays on What It Means to be Equals, Oxford: Oxford University Press, pp. 209-25. 